\title{
Nasopharyngeal Carcinoma with an uncommon Presentation
}

${ }^{1}$ Rajeev Gupta, ${ }^{2}$ Nariender K Mohindroo, ${ }^{3}$ Ramesh Azad

\begin{abstract}
Nasopharyngeal carcinoma (NPC) is a tumor arising from the epithelial cells that cover the surface and line of the nasopharynx. Symptoms of NPC can be obscure due to its anatomic location, which begins in the upper part of the pharynx behind the nose and ends at the proximal part of the trachea and esophagus. These include nasal, aural, and neurologic symptoms, thus often a challenge in diagnosis. Cervical lymphadenopathy is most commonly noted on physical examination, but sometimes rather spreading toward inferiorly it can spread toward superiorly and cause bone erosion and intracranial extension, which presents with visual impairment, proptosis, and cavernous sinus involvement. In this case report, we present a case of superiorly extended NPC without cervical lymphadenopathy presentation. As it is extremely radiosensitive, the best modality of treatment is radiotherapy.
\end{abstract}

Keywords: Cranial nerves, Nasopharyngeal carcinoma, Visual disturbance.

How to cite this article: Gupta R, Mohindroo NK, Azad R. Nasopharyngeal Carcinoma with an uncommon Presentation. Int J Head Neck Surg 2017;8(1):34-36.

\section{Source of support: Nil}

\section{Conflict of interest: None}

\section{INTRODUCTION}

Nasopharyngeal carcinoma (NPC) is a tumor arising from the epithelial cells that cover the surface and line of the nasopharynx. This tumor was first reported in 1901 and was clinically characterized in $1922 .{ }^{1,2}$ This tumor is uncommon in India, with the incidence of 0.9 per million. ${ }^{3}$ It is imperative to remember that although squamous cell carcinoma is the most common histological subtype of nasopharynx malignancy, it differs from other head and neck squamous cell carcinomas in epidemiology, etiology, histology, natural history, and response to treatment. ${ }^{4-7}$

Symptoms of NPC can be obscure due to its anatomic location, which begins in the upper part of the pharynx

\footnotetext{
${ }^{1}$ Resident, ${ }^{2}$ Professor and Head, ${ }^{3}$ Professor

${ }^{1-3}$ Department of ENT, Indira Gandhi Medical College, Shimla Himachal Pradesh, India

Corresponding Author: Rajeev Gupta, Resident, Department of ENT, Indira Gandhi Medical College, Shimla, Himachal Pradesh, India, Phone: +91-8894401387, e-mail: drrg87@ yahoo.co.in
}

behind the nose and ends at the proximal part of the trachea and esophagus. These include nasal, aural, and neurologic symptoms, thus often a challenge in diagnosis. Cervical lymphadenopathy is most commonly noted in physical examination. The majority of newly diagnosed NPC patients have locoregionally advanced disease, and cervical nodes are usually involved. ${ }^{8}$

Treatment is usually composed of a nonsurgical approach as the anatomic location is difficult to manage and in most cases, there is a locoregional disease; therefore, currently, the standard of care for these patients consists of concurrent chemoradiotherapy with cisplatinbased regimens, generally followed by adjuvant chemotherapy. ${ }^{8}$ This treatment approach results in a cure for the vast majority of patients, with 3-year disease-free and overall survival rates of approximately 70 and $80 \%$ respectively. Surgery is usually reserved for persistent or recurrent disease. ${ }^{8}$

\section{CASE REPORT}

A 65-years-old male was referred to the Indira Gandhi Medical College Shimla, India, with a complaint of headache, visual impairment for last 1 month. The patient had a previous history of nasal examination and biopsy about 1 month back at a local hospital. The patient had a headache following a biopsy which was dull aching in nature; the patient also had a history of nasal discharge from both the nasal cavity, which was mucoid in nature which was some time blood tinged. The patient had a history of giddiness. The patient had history of reduced vision from the right eye with drooping of the right eyelid. On neck examination, there was no cervical lymphadenopathy and swelling. On anterior rhinoscopy, there was deviated nasal septum toward the right side and yellowish mucoid discharge present in the bilateral nasal cavity. On eye examination, no ocular movement was present on right eye and there was complete ophthalmoplegia with severe ptosis. On visual acuity of the right eye, the perception of light was present and on the left side, there was no ocular movement toward left side and 6/24 on visual acuity. Hence, there was cranial nerve palsy of III, IV, VI on right side and VI nerve palsy on left side with visual impairment bilaterally (Fig. 1). The patient was posted for computed tomography (CT) scan of nose and paranasal sinuses, which showed large, abnormal soft 


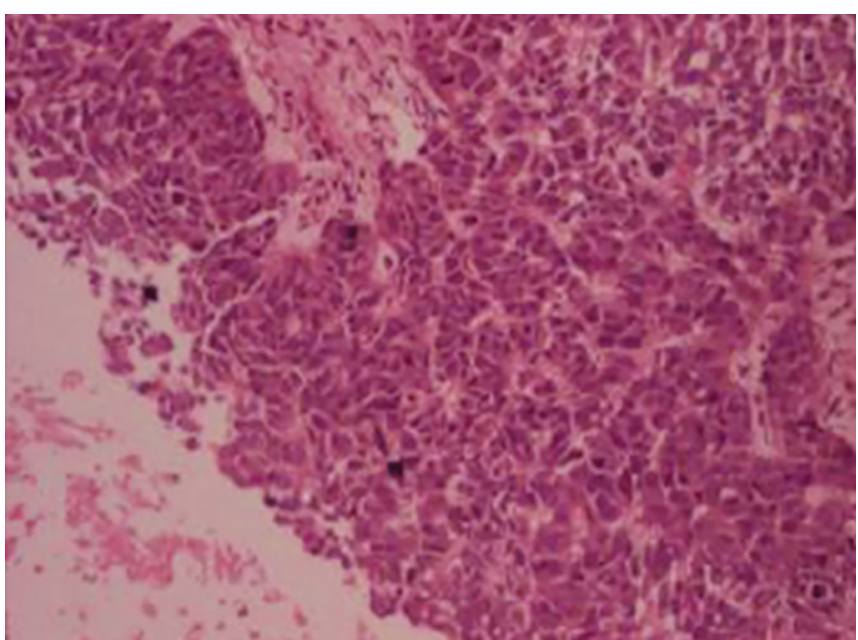

Fig. 1: Histopathological examination with sinonasal carcinoma (poorly differentiated carcinoma)

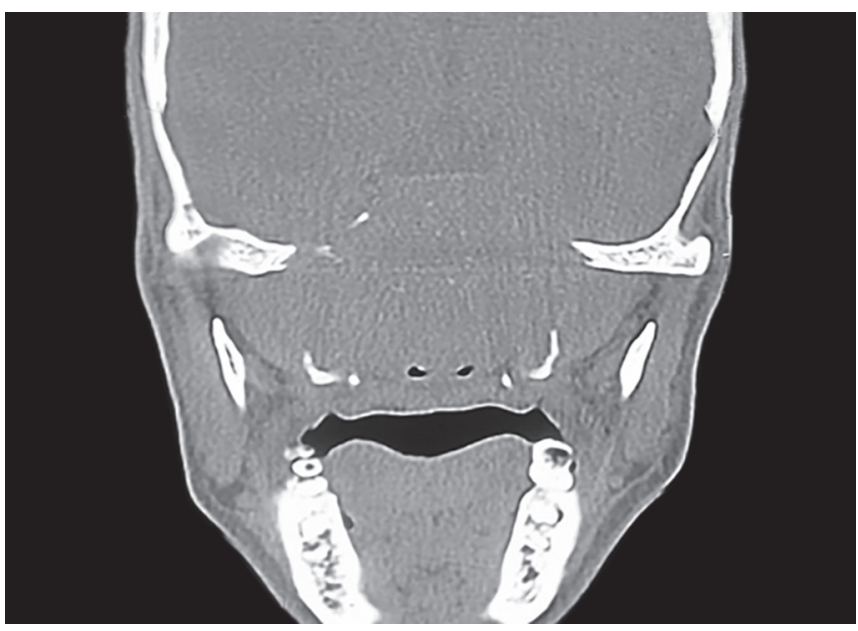

Fig. 3: Coronal view with extensive erosion of base of skull

tissue density calcified mass lesion in the nasopharyngeal region (Fig. 2). It is also extending in the bilateral nasal cavity along with intracranial extensions with destruction of sphenoid bone, clivus and basiocciput (Fig. 3) as well as petrous part of temporal bone.. The lesion was also seen in sella, bilateral temporal, and in prepontine cistern regions (Fig. 4). The lesion measured approximately $68 \times 67 \mathrm{~mm}$ in size. There were erosion and destruction of the bilateral maxilla. Interestingly, no cervical lymphadenopathy was seen in scans also.

Nasal endoscopy examination was done, which showed friable reddish mass at middle meatus region on both nasal cavities from which biopsy was taken and sent for histopathological examination (HPE). Interestingly, it showed poorly differentiated carcinoma with features suggestive of sinonasal carcinoma (Fig. 5).

As it was a very extensive lesion, radiotherapy opinion was taken and taxane, platinum, and 5-fluorouracil-based chemotherapy along with radiotherapy was started. Till now, the patient is showing a good response to treatment.

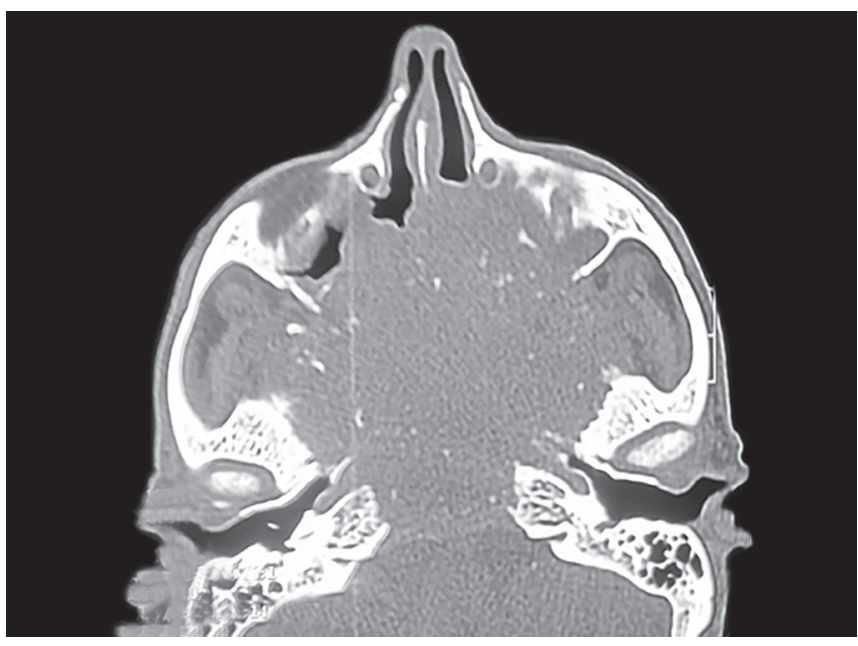

Fig. 2: Computed tomography scan with intracranial extensions

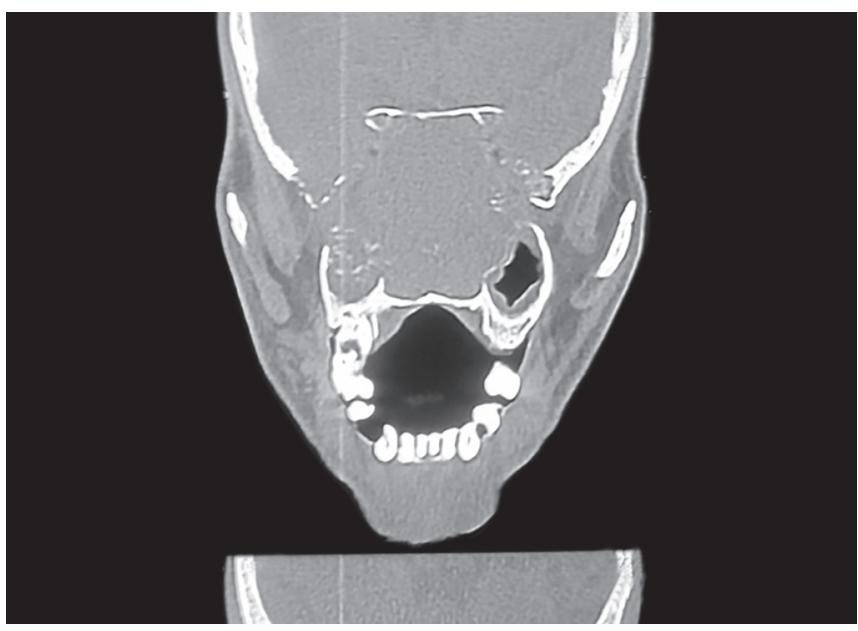

Fig. 4: Involvement of foramen ovale and cavernous sinus

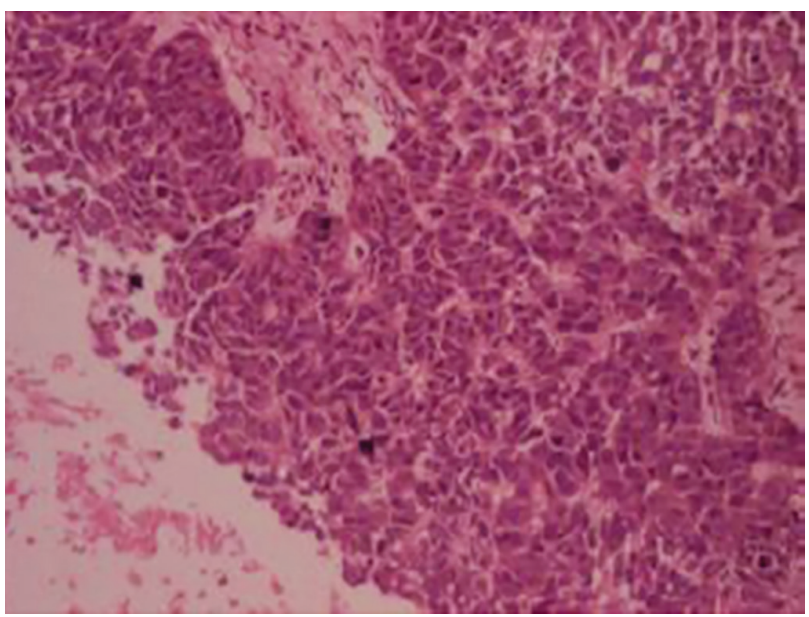

Fig. 5: Histopathological examination with poorly differentiated NPC

\section{DISCUSSION}

Despite the fact that NPC has a distinctive ethnic and geographic distribution, immigration is a common phenomenon and in some cases, the incidence may still be high in immigrants and offspring. ${ }^{4-7}$ 
Based on the degree of differentiation, the World Health Organization has classified NPC into three histopathologic types: Type I (typical keratinizing squamous cell carcinomas), type II (nonkeratinizing carcinoma), and type III (undifferentiated carcinoma most common). Types II and III may be accompanied by an inflammatory infiltrate of lymphocytes, plasma cells, and eosinophils, and these two types have also been called lymphoepithelioma. ${ }^{9,10}$

Tumors can grow within the nasopharynx or can spread anteriorly, laterally, posteriorly, superiorly, and inferiorly to the opposite lateral wall; they can also infiltrate other structures toward the base of the skull and invade the palate, nasal cavity, or the oropharynx. ${ }^{3,11-13}$ Skull-based invasion is the common presentation in up to one-third of cases ${ }^{12}$ and can be the initial presentation. ${ }^{13}$

The NPC can spread intracranially via the foramen lacerum or foramen ovale or through both the foramen ovale and foramen lacerum, and it also can spread by direct erosion, which results in multiple cranial deficits. ${ }^{13-15}$

Perineural spread through the foramen ovale is an important route, which explains CT scan evidence of cavernous sinus involvement (as in the present case CT scan showed the lesion in cavernous sinus area with bone erosion). ${ }^{16}$ However, on the examination of the nasopharynx, the lesion can be revealed as an exophytic mass or a smooth, mucosal-covered mass, with the fossa of Rosenmuller being the most common location; the diagnosis can be confirmed after histopathology., ${ }^{9,1}$

The NPC is not amenable to curative surgery because of its location, but it is a highly radiosensitive lesion. Therefore, radical external beam radiotherapy is the mainstay of treatment for this neoplasm and its regional metastasis. ${ }^{3,16}$

Despite the aggressive radiotherapy, the 5-year survival rate for locoregionally advanced disease at presentation is approximately 30 to $45 \%{ }^{17}$

\section{CONCLUSION}

Nasopharyngeal carcinoma is one of the most easily misdiagnosed tumors because it does not present with nasal symptoms: Rather, the patient may initially have unspecific signs and symptoms, such as headache, hearing loss, and facial pain. Most common presentation is with cervical lymphadenopathy, but sometimes rather than spreading toward inferiorly, it can spread toward superiorly and cause bone erosion and intracranial extension, which presents with visual impairment, proptosis, and cavernous sinus involvement. As it is extremely radiosensitive, best modality of treatment is radiotherapy.

\section{REFERENCES}

1. Regaud C. Lympho-épitheliome de l'hypopharynx traité par la roentgenthérapie. Bull Soc Franc Otorhinolaryngol 1921;34:209-214.

2. Schmincke A. Über lymphoepitheliale Geschwülste. Beitr Pathol Anat 1921;68:161-170.

3. Brennan B. Nasopharyngeal carcinoma. Orphanet J Rare Dis 2006 June;26(1):23.

4. Ferlay J, Bray F, Pisani P, Parkin DM. GLOBOCAN 2002: Cancer incidence, mortality and prevalence worldwide IARC CancerBase, No. 5, Version 2.0. Lyon, France: IARC Press; 2004.

5. Parkin DM, Iscovich J. Risk of cancer in migrants and their descendants in Israel: II. Carcinomas and germ-cell tumours. Int J Cancer 1997 Mar;70(6):654-660.

6. Bar-Sela G, Kuten A, Minkov I, Gov-Ari E, BenIzhak O. Prevalence and relevance of EBV latency in nasopharyngeal carcinoma in Israel. J Clin Pathol 2004 Mar;57(3):290-293.

7. Limand GCC, Yahaya H. Second report of the National Cancer Registry: cancer incidence in Malaysia, National Cancer Registry. Kuala Lumpur: Ministry of Health of Malaysia; 2003.

8. Razak ARA, Siu LL, Liu FF, Ito E, O'Sullivan B, Chan K. Nasopharyngeal carcinoma: the next challenges. Eur J Cancer 2010 Jul;46(11):1967-1978.

9. Wei WI, Sham JST, Choy D, Zong Y, Ng MH. The efficacy of fiberoptic endoscopic examination and biopsy in the detection of early nasopharyngeal carcinoma. Cancer 1991 June;67(12):3127-3130.

10. Chan JKC, Pilch BZ, Kuo TT, Wenig BM, Lee AWM. Tumors of the nasopharynx: Introduction. In: Barnes L, Eveson JW, Reichart P, Sidransky D, editors. Pathology and genetics of head and neck tumours (World Health Organization Classification of Tumours). Lyon, France: IARC Press; 2005. p. 82-84.

11. Jeyakumar A, Brickman TM, Jeyakumar A, Doerr T. Review of nasopharyngeal carcinoma. Ear Nose Throat J 2006 Mar;85(3):168-170, 172-173, 184.

12. Yang MS, Chen CC, Cheng YY, Hung HC, Chen WH, Lee MC, Lee CW, Lee SK. Nasopharyngeal carcinoma spreading along the eustachian tube: The imaging appearance. J Chin Med Assoc 2004 Apr;67(4):200-203.

13. Taguchi J, Sato M, Sasaki M, Ozaki M, Hanada M, Kuyama J, Hayakawa T. [A case with nasopharyngeal carcinoma extending into the cavernous sinus] [Article in Japanese]. No Shinkei Geka 1997 Oct;25(10):939-942.

14. Ampil FL, Heldmann M, Ibrahim AM, Balfour EL. Involvement of the cavernous sinus by malignant (extracranial) tumour: palliation in six cases without surgery. J Craniomaxillofac Surg 2000 Jun;28(3):161-164.

15. Ding JH, Hu CS, Peng WJ, Zhou ZR, Tang F, Mao J. [Evaluation of MRI in nasopharyngeal carcinoma with cavernous sinus infiltration] [Article in Chinese] Zhonghua Zhong Liu Za Zhi 2006 Jul;28(7):530-532.

16. Chong VF, Fan YF, Khoo JB. Nasopharyngeal carcinoma with intracranial spread: CT and MR characteristics. J Comput Assist Tomogr 1996 Jul-Aug;20(4):563-569.

17. Cooper JS, Lee H, Torrey M, Hochster H. Improved outcome secondary to concurrent chemoradiotherapy for advanced carcinoma of the nasopharynx: preliminary corroboration of the intergroup experience. Int J Radiat Oncol Biol Phys 2000 Jul;47(4):861-866. 